\title{
Isolation and mode of action of bacteriocin BacC1 produced by nonpathogenic Enterococcus faecium $\mathrm{C} 1$
}

\author{
H. F. Goh and K. Philip ${ }^{1}$ \\ Microbiology Division, Institute of Biological Sciences, Faculty of Science, University of Malaya, 50603 Kuala Lumpur, Malaysia
}

\begin{abstract}
Lactic acid bacteria are present in fermented food products and help to improve shelf life and enhance the flavor of the food. They also produce metabolites such as bacteriocins to prevent the growth of undesirable or pathogenic bacteria. In this study, Enterococcus faecium $\mathrm{C} 1$ isolated from fermented cow milk was able to produce bacteriocin $\mathrm{BacC} 1$ and inhibit the growth of selected food-spoilage bacteria. The bacteriocin was purified through 4 steps: ammonium sulfate precipitation, hydrophobic interaction column, a series of centrifugal steps, and finally reversed-phase HPLC. A membrane permeability test using SYTOX green dye (Invitrogen, Grand Island, NY) showed that the bacteriocin caused significant disruptions to the test bacterial membrane, as shown by transmission electron microscopy. The molecular weight of the BacC1 obtained from SDS-PAGE was around $10 \mathrm{kDa}$, and $\mathrm{N}$-terminal sequencing revealed a partial amino acid sequence of BacC1: GPXGPXGP. The bacterial strain was nonhemolytic and not antibiotic resistant. Therefore, it has high potential for application in the food industry as an antimicrobial agent to extend the shelf life of food products.
\end{abstract}

Key words: lactic acid bacteria, bacteriocin, fermented milk

\section{INTRODUCTION}

Lactic acid bacteria (LAB) are generally recognized as safe (GRAS) microorganisms and have been used in food fermentation for a long time (Stiles and Holzapfel, 1997). During fermentation, LAB utilize the sugar in food to produce end products such as lactic acid, hydrogen peroxide, diacetyl, and other organic acids that prevent the growth of spoilage bacteria. The production of bacteriocins by some LAB also contributes to the inhibition of spoilage bacteria, thereby extending the shelf life of the food (Deegan et al., 2006). Enterococcus is one of the prominent genera among LAB that can

Received December 15, 2014.

Accepted April 11, 2015.

${ }^{1}$ Corresponding author: kphil@um.edu.my produce diverse antimicrobial peptides within a single strain (Izquierdo et al., 2009).

Enterococci are found in many foods such as dairy products, fermented sausages, and olives (Ben Omar et al., 2004). Enterococci are now being used as probiotics but they are also among the most common nosocomial pathogens associated with many human infections. They are known to cause endocarditis, bacteremia, and urinary tract, central nervous system, intraabdominal, and pelvic infections, and can cause multiple antibiotic resistance. The number of vancomycin-resistant enterococci is increasing. However, enterococci that possess virulence genes are only isolated from patients (Franz et al., 2003; Foulquié Moreno et al., 2006). Most of the pathogenic strains are multi-antibiotic resistant and produce adhesins, invasins, pili, and hemolysin, causing bacteremia, endocarditis, and other infections (Franz et al., 2011; Rehaiem et al., 2014).

The LAB are known to produce bacteriocins, which are antimicrobial peptides that can inhibit the growth of closely related microorganisms and certain foodspoilage microorganisms, including Listeria monocytogenes, Staphylococcus aureus, Bacillus subtilis, and spores of Clostridium perfringens (Klaenhammer, 1993; du Toit et al., 2000). Producer strains of bacteriocins have a specific immunity mechanism to protect them from their own bacteriocins. These bacteriocins can also be produced in situ in the human gut by producer strains to combat intestinal infections (Cotter et al., 2013). Bacteriocins can be generally divided into 3 classes. Class I consists of lantibiotics, which are of low molecular weight and include lanthionine and $\beta$-methyllanthionine. Class II comprises heat-stable unmodified bacteriocins further sub-divided into 3 classes; namely, class IIa (Listeria active peptides), class IIb (2-peptide bacteriocins), and class IIc (cyclic peptides). Class III comprises high-molecular-weight and heat-labile bacteriocins (Yi et al., 2010).

In this paper, we describe a bacteriocin produced by Enterococcus faecium $\mathrm{C} 1$ isolated from fermented cow milk. This bacteriocin is a high-molecular-weight peptide with a broad inhibitory spectrum capable of permeabilizing the cell walls of target bacteria. In this study, gram-positive and gram-negative bacteria 
were used in initial screening for antimicrobial activity. Toward the end of purification, we focused on the inhibitory activity of $B$. cereus. The occurrence of $B$. cereus in milk product is frequently reported because of its psychrotrophic and spore-forming characteristics. Bacillus cereus can survive even after pasteurization, affecting the shelf life of pasteurized milk, and consumption of milk contaminated with B. cereus can cause food poisoning (Andersson et al., 1995; Christiansson et al., 1999).

\section{MATERIALS AND METHODS}

\section{Media, Culture Conditions, and Producer Strain Identification}

The bacteriocin producer Enterococcus faecium C1 was isolated from fermented cow milk obtained from Malaysian retail outlets and grown on de Man, Rogosa, Sharpe (MRS) agar (Merck, Darmstadt, Germany) aerobically at $37^{\circ} \mathrm{C}$. The producer strain was identified by API 20 Strep (bioMérieux, Marcy l'Etoile, France) and 16S rRNA gene sequencing by using universal $27 \mathrm{~F}$ and $1492 \mathrm{R}$ primers. The sequence was compared with National Center for Biotechnology Information (NCBI) nucleotide blast search database (http:// blast.ncbi.nlm.nih.gov/Blast.cgi) and the sequence was deposited in the database. The medium used to produce the bacteriocin was LAPTg broth (Pingitore et al., 2007) and that used for culture maintenance was MRS agar. The target bacteria; namely, Bacillus cereus ATCC14579, Escherichia coli UT181, Listeria monocytogenes NCTC10890, Micrococcus luteus ATCC10240, Pseudomonas aeruginosa PA7, and Staphylococcus aureus RF122 were cultured in Mueller-Hinton broth (Merck). These cultures were obtained originally from American Type Culture Collection (Manassas, VA) and maintained in the Microbiology Division, Institute of Biological Sciences, University of Malaya (Kuala Lumpur, Malaysia).

\section{Hemolysis and Antibiotic Susceptibility Test}

The producer strain was grown overnight on MRS agar (Merck) at $37^{\circ} \mathrm{C}$ and subcultured again on blood agar base (Difco France, Bordeaux, France) containing $7 \%$ (vol/vol) sheep blood incubated at $37^{\circ} \mathrm{C}$ overnight. The hemolysis activity was recorded as $\alpha$-hemolysis (agar under the colony became dark and greenish), $\beta$-hemolysis (clear zone around the colonies), or $\gamma$-hemolysis (unchanged). Antibiotic susceptibility test of E. faecium $\mathrm{C} 1$ was done based on standards from Clinical and Laboratory Standards Institute (CLSI, 2007; volume 27). A bacterial suspension equivalent to
0.5 McFarland standard was seeded on Mueller-Hinton agar and antibiotic discs were overlaid on the surface of the agar. The plates were incubated at $37^{\circ} \mathrm{C}$ for $18 \mathrm{~h}$ and longer $(24 \mathrm{~h})$ for the vancomycin disc. The growth of the bacteria inhibited by the antibiotic discs was indicated by halo zones appearing around the discs. The diameter of the zone of inhibition was reported in millimeters. Results were reported as $\mathrm{S}$ (sensitive), I (intermediate), or R (resistant) according to CLSI (2007) breakpoints. The antibiotic discs (Oxoid, Basingstoke, UK) used were amoxicillin $(10 \mu \mathrm{g})$, ampicillin $(10 \mu \mathrm{g})$, chloramphenicol $(30 \mu \mathrm{g})$, clindamycin $(2 \mu \mathrm{g})$, gentamicin $(10 \mu \mathrm{g})$, novobiocin $(5 \mu \mathrm{g})$, ofloxacin $(5 \mu \mathrm{g})$, penicillin $\mathrm{G}$ (1 unit), penicillin $\mathrm{V}(10 \mu \mathrm{g})$, streptomycin $(10 \mu \mathrm{g})$, tetracycline $(30 \mu \mathrm{g})$, and vancomycin $(30 \mu \mathrm{g})$.

\section{Bacteriocin Purification}

The producer strain was grown in $1 \mathrm{~L}$ of LAPTg broth for $18 \mathrm{~h}$ at $37^{\circ} \mathrm{C}$. The fermented broth was centrifuged at $10,000 \times g$ for 20 min after which the bacterial pellet was discarded. Ammonium sulfate (Merck) was added slowly to the cell-free supernatant until the solution reached $80 \%$ saturation and then stirred overnight at $4^{\circ} \mathrm{C}$. The product was then centrifuged at $10,000 \times g$ for 15 min and the supernatant discarded. The precipitate was dissolved in a minimal amount of sterile double-distilled water. Then, the sample was loaded into Amberlite XAD 16 resin (Sigma-Aldrich, St. Louis, MO), a hydrophobic resin packed in a filtration column, and washed with $1 \mathrm{~L}$ of sterile distilled water, after which the fractions were eluted out by gradually increasing the concentration of acetonitrile from 10 to 50 to $90 \%$. The active fractions from the XAD column were further fractionated by size using Vivaspin (Sartorius, Göttingen, Germany) with different molecular weight cut-offs (MWCO) specifically at $0.2 \mu \mathrm{m}: 1,000,000,50,000$, and 5,000 MWCO. The ammonium sulfate precipitate $(50 \mu \mathrm{L})$ was tested against Bacillus cereus ATCC14579, Escherichia coli UT181, Listeria monocytogenes NCTC10890, Micrococcus luteus ATCC10240, Pseudomonas aeruginosa PA7, and Staphylococcus aureus RF122 using the well diffusion method with 5-mm-diameter wells made by a cork borer. Bacillus cereus was selected as the target bacteria in the subsequent steps of purification. The antimicrobial test for Vivaspin fraction was performed by spotting 20 $\mu \mathrm{L}$ of the fraction on Mueller-Hinton agar seeded with B. cereus.

\section{Reversed-Phase HPLC}

The fraction collected from Vivaspin column was loaded into HPLC equipped with Chromolith SemiPrep 
RP-18e column (Merck) and EMPOWER software for data control and processing (Waters, Milford, MA). The separation was carried out by linear biphasic gradient separation using 2 mobile phases: mobile phase A was Milli-Q water (Millipore, Billerica, MA) and B was acetonitrile (ACN; Merck). All solutions were filtered through a nylon filter of pore size $0.45 \mu \mathrm{m}$. The flow rate of the mobile phase was set at $1 \mathrm{~mL} / \mathrm{min}$. A gradient was used starting with $0 \%$ of solution B, $40 \%$ of solution B after 3 min, and $100 \%$ of solution B after $45 \mathrm{~min}$. Upon completion of the separation, the system remained unchanged for the next $5 \mathrm{~min}$ and then returned to $100 \%$ solution A (column rinsing). Elution was monitored at wavelength $214 \mathrm{~nm}$ and fractions were collected manually at 3-min intervals. Fractions that exhibited antimicrobial activity were collected at the same retention time during different HPLC runs and then pooled and lyophilized. The purified bacteriocin was named BacC1.

\section{Heat, $p H$, and Enzyme Stability Tests}

The bacteriocin BacC1 collected from the HPLC fraction was exposed to variable temperatures of 40,60 , 80 , and $100^{\circ} \mathrm{C}$ for $20 \mathrm{~min}$ each. The heated bacteriocins were then cooled to room temperature and tested for inhibition on Mueller-Hinton agar seeded with $B$. cere$u s$. The bacteriocin was adjusted to a $\mathrm{pH}$ value ranging from 2 to 10 by using concentrated sodium hydroxide $(\mathrm{NaOH})$ and hydrogen chloride ( $\mathrm{HCl}$; Merck). After adjusting the $\mathrm{pH}$, the bacteriocin was incubated at $25^{\circ} \mathrm{C}$ for $2 \mathrm{~h}$, after which antimicrobial activity was tested by the agar well diffusion method with 5 -mm-diameter wells. The sensitivity of the bacteriocin toward different enzymes (proteinase K, lysozyme, lipase, catalase, lyticase, trypsin, and peptidase) was also tested; $500 \mu \mathrm{L}$ of the bacteriocin was treated with enzymes prepared at a final concentration of $1 \mathrm{mg} / \mathrm{mL}$, and a control without enzyme was used. All preparations were incubated at $37^{\circ} \mathrm{C}$ for $1 \mathrm{~h}$ and then tested against B. cereus.

\section{Membrane Permeabilization Test}

Membrane permeabilization assay was carried out using SYTOX green fluorescent dye (Invitrogen, Grand Island, NY). This molecular probe can only permeate depolarized membranes and is a high-affinity DNA stain that cannot enter intact bacterial membranes. The target bacterium B. cereus was grown in MuellerHinton broth for $18 \mathrm{~h}$ at $37^{\circ} \mathrm{C}$. The bacterial pellets were washed twice with $10 \mathrm{~m} M$ sodium phosphate buffer, $\mathrm{pH} 7.2$, before resuspending in the same buffer to attain an optical density of 0.6 at a wavelength of 600 $\mathrm{nm}$. Then, $5 \mu \mathrm{L}$ of SYTOX green stock solution was added to $5 \mathrm{~mL}$ of $B$. cereus to give a final concentration of $5 \mu M$ of SYTOX green. Ninety microliters of the bacteria added with SYTOX green was mixed with 10 $\mu \mathrm{L}$ of bacteriocin BacC1 at different ratios (2:1, 1:2, and 1:32). The positive control used was $1 M$ sodium hydroxide and the negative control was bacterial cells without bacteriocin. Tetracycline $(1.5 \mu \mathrm{g} / \mathrm{mL})$ was also tested as a known antimicrobial having a different mode of action. The experiment was performed in quadruplicate and run at $37^{\circ} \mathrm{C}$ for $60 \mathrm{~min}$. The wells were sealed by using an adhesive cover and the plate was placed immediately in the Step One Plus real-time PCR system (Applied Biosystem, Waltham, MA). The raw data were analyzed using Microsoft Excel software (Microsoft Corp., Redmond, WA), and the fluorescence uptake of each treatment was plotted.

\section{Effect of the Bacteriocin BacC1 on Bacteria Under Transmission Electron Microscope}

The test bacteria were treated with a final concentration of $1,000 \mu \mathrm{g} / \mathrm{mL}$ bacteriocin $\mathrm{BacC} 1$ from the HPLC fraction and incubated for $3 \mathrm{~h}$ at $37^{\circ} \mathrm{C}$. Bacteria without addition of bacteriocin were prepared and used as a negative control. Then, the bacteriocin was washed 3 times by using sodium phosphate buffer and centrifuging at $2,000 \times g$ for $15 \mathrm{~min}$. The cells were fixed with $4 \%$ glutaraldehyde and left overnight at $4^{\circ} \mathrm{C}$. The samples were then washed 3 times with cacodylate buffer and post-fixed for $2 \mathrm{~h}$ with osmium tetroxide and cacodylate buffer in a 1:1 ratio. Then, the samples were repeatedly washed with cacodylate buffer 3 times and left in cacodylate buffer overnight. After overnight incubation, the samples were washed 3 times with water, washed with uranyl acetate, and finally washed with distilled water. The samples were dehydrated in a graded ethanol series and embedded in epon, which was used as an embedding resin. Ultrathin sections $(0.1$ $\mu \mathrm{m})$ were prepared and coated on copper grids. The coated samples were then stained with uranyl acetate and lead citrate. The grids were examined using a LEO-Libra 120 transmission electron microscope (Carl Zeiss, Oberkochen, Germany).

\section{SDS-PAGE and Matrix-Assisted Laser Desorption/ Ionization Time-of-Flight Analysis}

The molecular weight of the active HPLC fraction was estimated using SDS-PAGE. The gel used for the separation was $16.5 \%$ Tris-tricine SDS-PAGE gel and the ladder used was Precision Plus Protein Dual Xtra Standards (Bio-Rad, Hercules, CA). Electrophoresis was conducted at $100 \mathrm{mV}$ for $1.5 \mathrm{~h}$. The gel was stained with SimplyBlue SafeStain (Invitrogen, Paisley, UK) 
after washing 3 times with distilled water. The band from SDS-PAGE was cut and digested with trypsin by shaking the gel plugs 3 times in $50 \mu \mathrm{L}$ of $50 \% \mathrm{ACN}$ containing $50 \mathrm{mM}$ ammonium bicarbonate until the gel became clear. The gel plug was incubated in $150 \mu \mathrm{L}$ of $10 \mathrm{~m} M$ dithiothreitol in $100 \mathrm{~m} M$ ammonium bicarbonate for $30 \mathrm{~min}$ at $60^{\circ} \mathrm{C}$. Then, the gel plug was cooled to room temperature and the alkylation and dehydration step continued. The gel was digested with trypsin. The sample was extracted and desalted with Zip-Tip (C18, Millipore, Bedford, MA) before subjecting to matrixassisted laser desorption/ionization tandem time-offlight (MALDI TOF/TOF; ABI 4800 Plus, Applied Biosystems, Foster City, CA).

\section{Amino-Terminal Sequence Analysis}

The N-terminal amino acids of the purified bacteriocin BacC1 were sequenced by Edman degradation using a Procise 494 sequencer (Applied Biosystems) equipped with a PTH-C18 column (Applied Biosystems, Roissy, France) for the quantitative determination of phenylthiohydantoin (PTH) amino acids.

\section{Genome Sequencing and Analysis}

DNA with required quality and quantity was isolated with DNeasy Blood and Tissue Kits (Qiagen, Valencia, CA) followed the manufacturer's instruction. The concentration of DNA of each sample was measured with Qubit (Invitrogen) and Nanodrop spectrophotometer (Thermofisher, Waltham, MA). The DNA was then fragmented using the Covaris S220 system (Applied Biosystems) to fragment it into a size range of 600 to $900 \mathrm{bp}$ following optimized conditions. A DNA library (using $800 \mathrm{ng}$ of sonic cleaned DNA) was prepared using Nextflex DNA Sample Prep Kit (Bioo Scientific, Austin, TX) per the manufacturer's instructions. Library quality control was performed on Bioanalyzer (Agilent Technologies, Santa Clara, CA) to check the fragment size distribution. The quality control-passed library was sequenced on MiSeq sequencer (Illumina Inc., San Diego, CA) with MiSeq Reagent Kits v3 (300 cycle, paired-end). Fluorescent images were analyzed using the MiSeq Control Software, and FASTQ-formatted sequence data were created using MiSeq Reporter Analysis. Basic analysis was performed with RAST server (http://rast.nmpdr.org/). The analysis focused on the search of genes encoding bacteriocin production, high-molecular-weight bacteriocin (more than $5 \mathrm{kDa}$ ), antibiotic resistance genes, and virulence factors. Virulence genes listed in virulence factor database (VFDB; http://www.mgc.ac.cn/VFs/) were searched using the BLAST database with the genome sequence obtained.
Five categories of virulence factors were covered including adherence, antiphagocytosis, biofilm formation, exoenzyme (gelatinase, hyaluronidase and serine protease), and toxin (cytolysin) production.

\section{RESULTS}

\section{Producer Strain Identification}

The 16S rRNA gene sequence of the strain showed that it shared $99 \%$ similarity with Enterococcus faecium by NCBI nucleotide BLAST, and $99.4 \%$ similarity with Enterococcus faecium was achieved with API 20 Strep. The 16S rRNA gene sequence of the strain was deposited in the NCBI database under accession number KJ675503.

\section{Hemolysis and Antibiotic Susceptibility Test}

Enterococcus faecium used in this study showed $\gamma$-hemolysis; that is, the blood agar remained unchanged. No clear zone surrounding the colony could be seen after $24 \mathrm{~h}$ of incubation, indicating absence of hemolysis. The results of antibiotic disc test revealed that E. faecium was not resistant to vancomycin or ampicillin and was susceptible to most of the antibiotics listed in the CLSI (2007) standard (Table 1). The breakpoints of clindamycin and ofloxacin were obtained from Streptococcus spp., which was the most closely related species to Enterococcus spp. According to the CLSI breakpoint, the strain is susceptible to ofloxacin but resistant to clindamycin. However, amoxicillin, novobiocin, and penicillin $\mathrm{G}$ tested in this study were not listed in the CLSI standard. The inhibition zones for amoxicillin and novobiocin showed that the strain was sensitive to both antibiotics. On the other hand, the inhibition zone for penicillin $G$ was much smaller than that for other antibiotics; hence, the quantity of penicillin G (1 unit) used was not enough to kill the bacteria.

\section{Bacteriocin Purification}

The ammonium sulfate precipitate showed significant activity on B. cereus, E. coli, P. aeruginosa, and $M$. luteus, but it was not active against $L$. monocytogenes and $S$. aureus (Table 2). The activity remained after purification with Amberlite XAD 16 column and inhibition zones were observed at 50 and $90 \%$ acetonitrile elution (Figure 1). The active fractions were combined and separated by size using Vivaspin centrifugal concentrators. After a series of separations from high to low molecular weights, the final fractions of 5 to 50 $\mathrm{kDa}$ (upper fraction for $5 \mathrm{kDa}$ Vivaspin cutoff) and $<5$ 
Table 1. Antibiotic susceptibility test of Enterococcus faecium

\begin{tabular}{|c|c|c|c|c|c|}
\hline \multirow[b]{2}{*}{ Antibiotic } & \multirow{2}{*}{$\begin{array}{l}\text { E. faecium } \\
\text { inhibition } \\
\text { zone }(\mathrm{mm})\end{array}$} & \multicolumn{3}{|c|}{ CLSI breakpoint $^{1}$} & \multirow[b]{2}{*}{ Interpretation } \\
\hline & & $\mathrm{R}$ & I & S & \\
\hline Amoxicillin, $10 \mu \mathrm{g}$ & 17.46 & - & - & - & $\mathrm{NA}^{2}$ \\
\hline Ampicillin, $10 \mu \mathrm{g}$ & 17.62 & $\leq 16$ & — & $\geq 17$ & $\mathrm{~S}$ \\
\hline Chloramphenicol, $30 \mu \mathrm{g}$ & 18.30 & $\overline{\leq} 12$ & $13-17$ & $\geq 18$ & $\mathrm{~S}$ \\
\hline Clindamycin, $2 \mu \mathrm{g}$ & 7.30 & $\leq 15^{3}$ & $16-18^{3}$ & $\geq 19^{3}$ & $\mathrm{R}$ \\
\hline Gentamicin, $10 \mu \mathrm{g}$ & 12.16 & $6^{4}$ & $7-9^{4}$ & $\geq 10^{4}$ & $\mathrm{~S}$ \\
\hline Novobiocin, $5 \mu \mathrm{g}$ & 14.20 & - & - & - & NA \\
\hline Ofloxacin, $5 \mu \mathrm{g}$ & 16.08 & $\leq 12^{3}$ & $13-15^{3}$ & $\geq 16^{3}$ & $\mathrm{~S}$ \\
\hline Penicillin G, 1 unit & 7.06 & - & - & - & NA \\
\hline Penicillin V, $10 \mu \mathrm{g}$ & 15.92 & $\leq 14$ & - & $\geq 15$ & $\mathrm{~S}$ \\
\hline Streptomycin, $10 \mu \mathrm{g}$ & 12.22 & $6^{4}$ & $7-9^{4}$ & $\geq 10^{4}$ & $\mathrm{~S}$ \\
\hline Tetracycline $30 \mu \mathrm{g}$ & 22.26 & $\leq 14$ & $15-18$ & $\geq 19$ & S \\
\hline Vancomycin, $30 \mu \mathrm{g}$ & 18.34 & $\leq 14$ & $15-16$ & $\geq 17$ & S \\
\hline
\end{tabular}

${ }^{1} \mathrm{~S}=$ susceptible, $\mathrm{I}=$ intermediate, $\mathrm{R}=$ resistant.

${ }^{2} \mathrm{NA}=$ no guidelines were available for this antibiotic-bacteria combination.

${ }^{3}$ Clinical and Laboratory Standards Institute (CLSI) breakpoint obtained from Streptococcus spp.

${ }^{4}$ Breakpoint for high-level aminoglycoside resistance (HLAR).

$\mathrm{kDa}$ (lower fraction for $5 \mathrm{kDa}$ Vivaspin cutoff) were obtained. The spot-on-lawn of the fractions showed that fraction 5 to $50 \mathrm{kDa}$ showed significant inhibition against $B$. cereus, whereas no inhibitory activity was observed for the fraction of $<5 \mathrm{kDa}$ (Figure 2).

\section{Reversed-Phase HPLC}

All fractions from the HPLC run were tested and the fraction obtained at a retention time between 33 and 36 min was shown to inhibit the growth of $B$. cereus. This fraction consisted of 4 peaks and was eluted with 30 to $32 \%$ ACN (Figure 3). The runs were repeated to collect replicate samples of the bacteriocin and then lyophilized using the same retention time for the subsequent tests.

\section{Heat, pH, and Enzyme Stability Tests}

The bacteriocin BacC1 was heat stable and remained active against the test bacteria after heating to $40^{\circ} \mathrm{C}$ and $60^{\circ} \mathrm{C}$ for $20 \mathrm{~min}$. However, the activity of the

Table 2. Antimicrobial assay of the Enterococcus faecium isolate against different test bacteria

\begin{tabular}{lc}
\hline Test bacteria & E. faecium \\
\hline Bacillus cereus ATCC14579 & +++ \\
Escherichia coli UT181 & ++ \\
Listeria monocytogenes NCTC10890 & - \\
Pseudomonas aeruginosa PA7 & +++ \\
Staphylococcus aureus RF122 & - \\
Micrococcus luteus ATCC10240 & +++ \\
\hline
\end{tabular}

${ }^{1}+++=$ antimicrobial activity with inhibition zone $>12 \mathrm{~mm},++=$ antimicrobial activity with inhibition zone $<12 \mathrm{~mm} ;-=$ no antimicrobial activity.
BacC1 was reduced after heating to $80^{\circ} \mathrm{C}$ and $100^{\circ} \mathrm{C}$. It was stable at low $\mathrm{pH}$ from 2 to 6 and activity was lost at $\mathrm{pH}$ values $>6$. The enzyme stability test showed that the $\mathrm{BacC} 1$ was sensitive to proteinase $\mathrm{K}$ and peptidase because reduction of activity was observed in BacC1 treated with both enzymes (Supplementary Table S1; http://dx.doi.org/10.3168/jds.2014-9240). The bacteriocin remained active after treatment with lysozyme, lipase, catalase, lyticase, and trypsin.

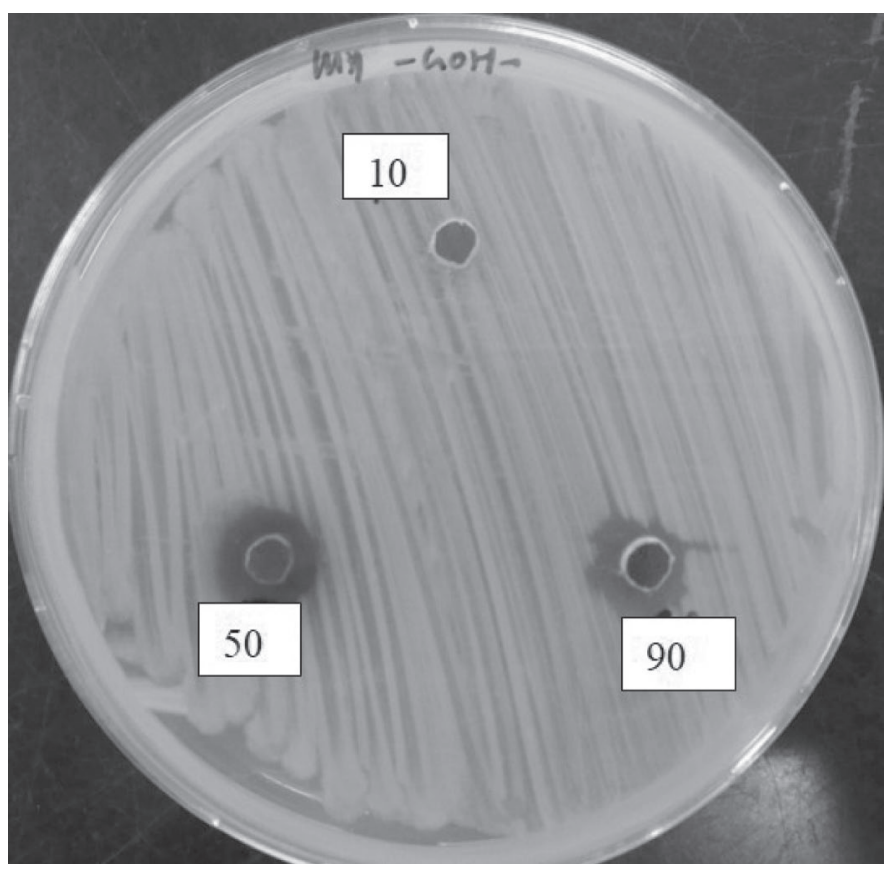

Figure 1. Antimicrobial activity of different fractions from Amberlite XAD 16 column (Sigma-Aldrich, St. Louis, MO). Samples were eluted with 10,50 , and $90 \%$ acetonitrile against Bacillus cereus. 


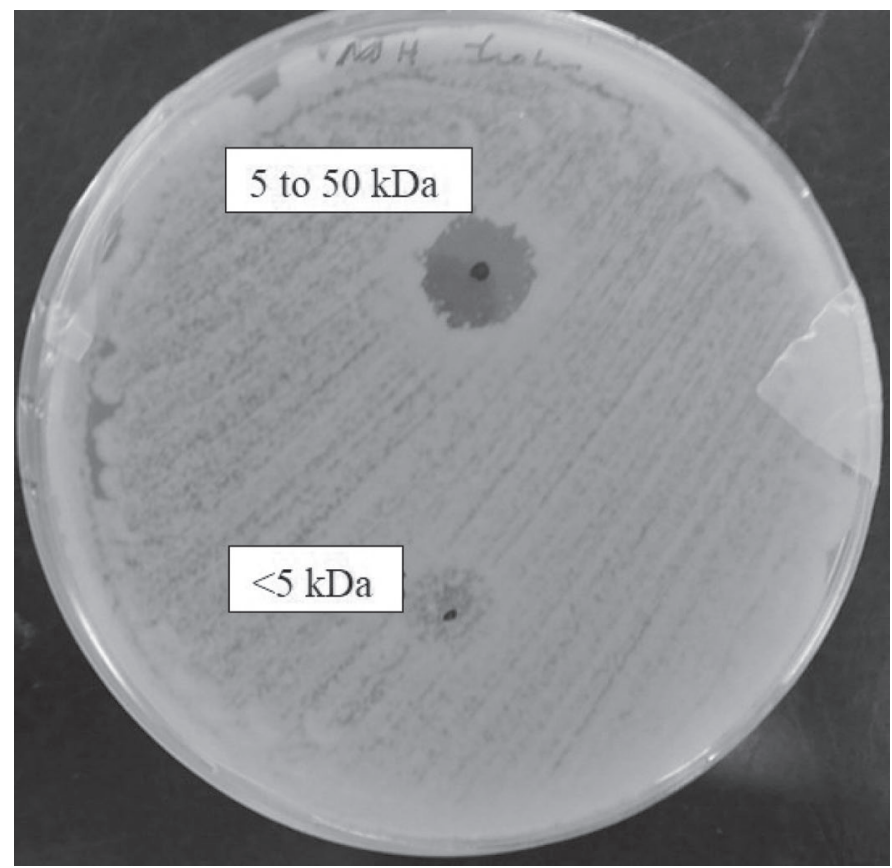

Figure 2. Antimicrobial activity of 2 fractions of bacteriocins from Enterococcus faecium (5 to $50 \mathrm{kDa}$ and $<5 \mathrm{kDa}$ ).

\section{Membrane Permeabilization Test}

The membrane permeabilization test with SYTOX green dye showed a significant difference between posi- tive and negative controls in permeabilizing bacterial cell membranes (Figure 4). Sodium hydroxide (used as the positive control) showed high fluorescence, whereas the 2 negative controls used in this study (tetracycline and blank) showed low fluorescence. The fluorescence unit for BacC1 from E. faecium with dilutions 2:1, $1: 1$, and 1:32 also indicated membrane disruption on $B$. cereus. Fluorescence decreased when the dilution of the bacteriocin increased. The disruption of the bacterial membrane allowed the SYTOX green dye to pass through the membrane and incorporate with the bacterial DNA, resulting in a fluorescent signal.

\section{Effect of Bacteriocin BacC1 on Bacteria Under Transmission Electron Microscope}

Figure 5a shows that the control cell had an intact cell membrane without any disruption; after treatment with the bacteriocin, the cell walls of some of the test bacteria were broken down (Figure 5b) and others appeared as dense cytoplasm without any cell wall (Figure $5 \mathrm{c})$.

\section{SDS-PAGE and Matrix-Assisted Laser Desorption/ Ionization Time-of-Flight Analysis}

The SDS-PAGE gel showed a clear band with molecular mass at around $10 \mathrm{kDa}$ (Figure 6). The band was cut and digested with trypsin. Protein identifica-

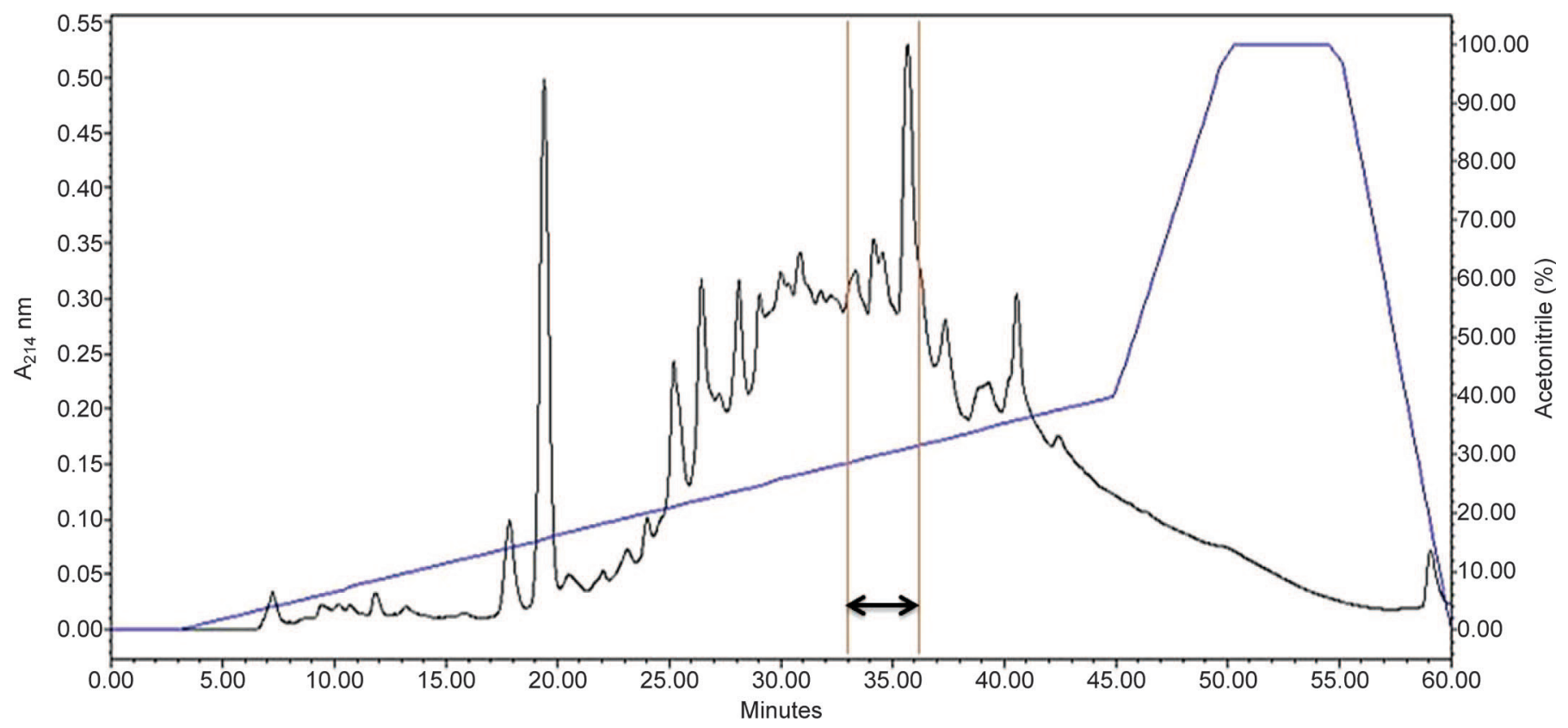

Figure 3. Reversed-phase HPLC profile of Vivaspin (Sartorius, Göttingen, Germany) fraction. The straight line indicates the percent concentration of acetonitrile and the vertical lines with a double arrow indicate the active fraction range. Color version available online. 


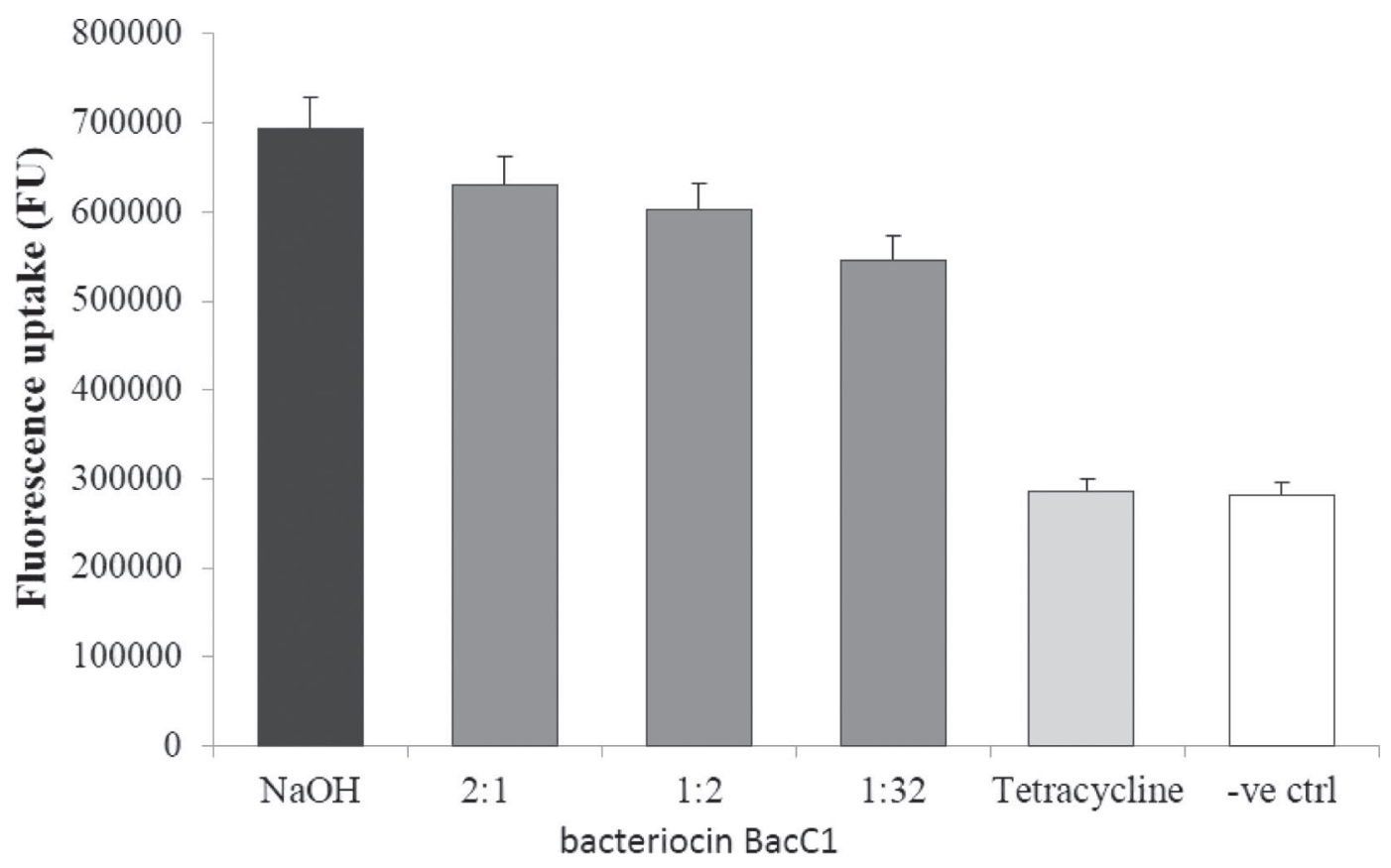

Antimicrobial agent

Figure 4. Fluorescence uptake of treatment with bacteriocin from Enterococcus faecium with dilution 2:1, 1:1, 1:32; negative (-ve) control, positive control $(1 \mathrm{M} \mathrm{NaOH})$, and tetracycline. Error bars represent standard deviations.

tion was performed by sending trypsin-digested bacteriocin molecular weights to the SWISS-PROT database (http://www.ebi.ac.uk/uniprot). Monoisotopic masses and a significance threshold of $P<0.05$ were used. No significant matching to the protein database was available, indicating $\mathrm{BacC} 1$ may be an unidentified novel protein (Supplementary Text; http://dx.doi. org/10.3168/jds.2014-9240).

\section{Amino-Terminal Sequence Analysis}

The N-terminal sequence analysis of the bacteriocin $\mathrm{BacC} 1$ determined the sequence of the first $8 \mathrm{AA}$ as follows: GPXGPXGP ( $\mathrm{G}=$ glycine, $\mathrm{P}=$ proline, $\mathrm{X}=$ hydroxyproline). Hydroxyproline is a structurally modified AA derived from proline. The sequence obtained did not match with any known bacteriocins. When the

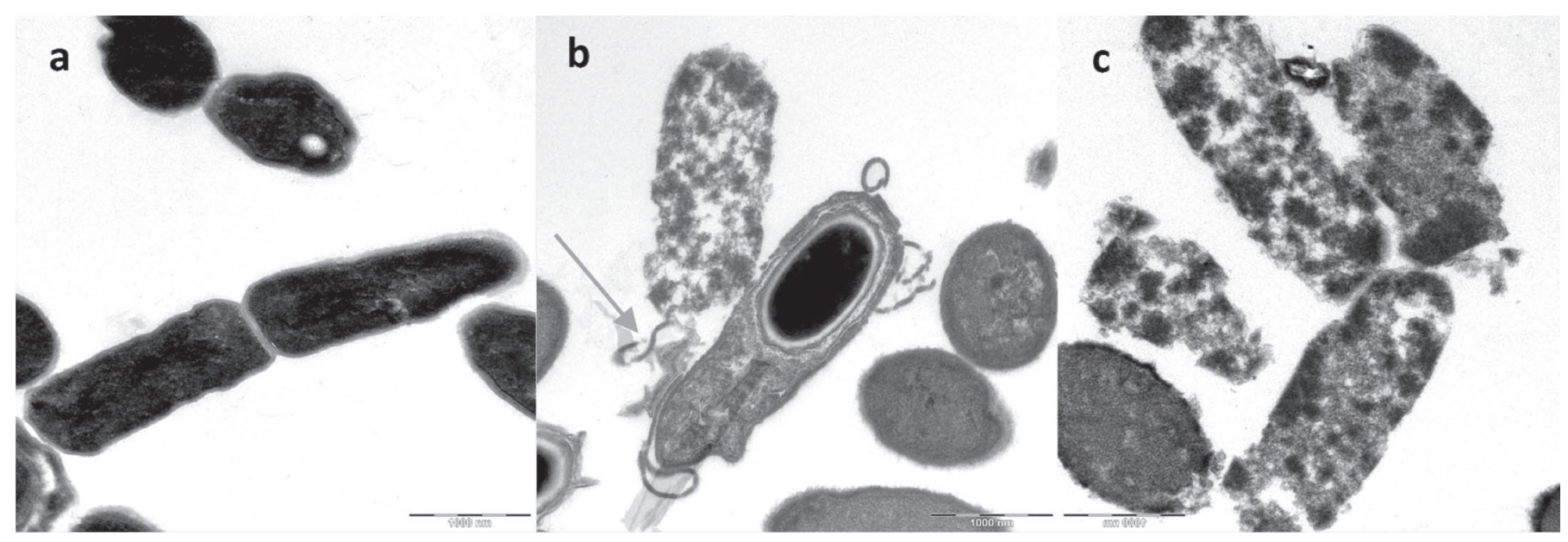

Figure 5. Transmission electron microscopy images of Bacillus cereus cells before (a) and after (b and c) treatment with bacteriocin from Enterococcus faecium. Bar indicates $1 \mu \mathrm{m}$. Arrows indicate destruction of membrane. 


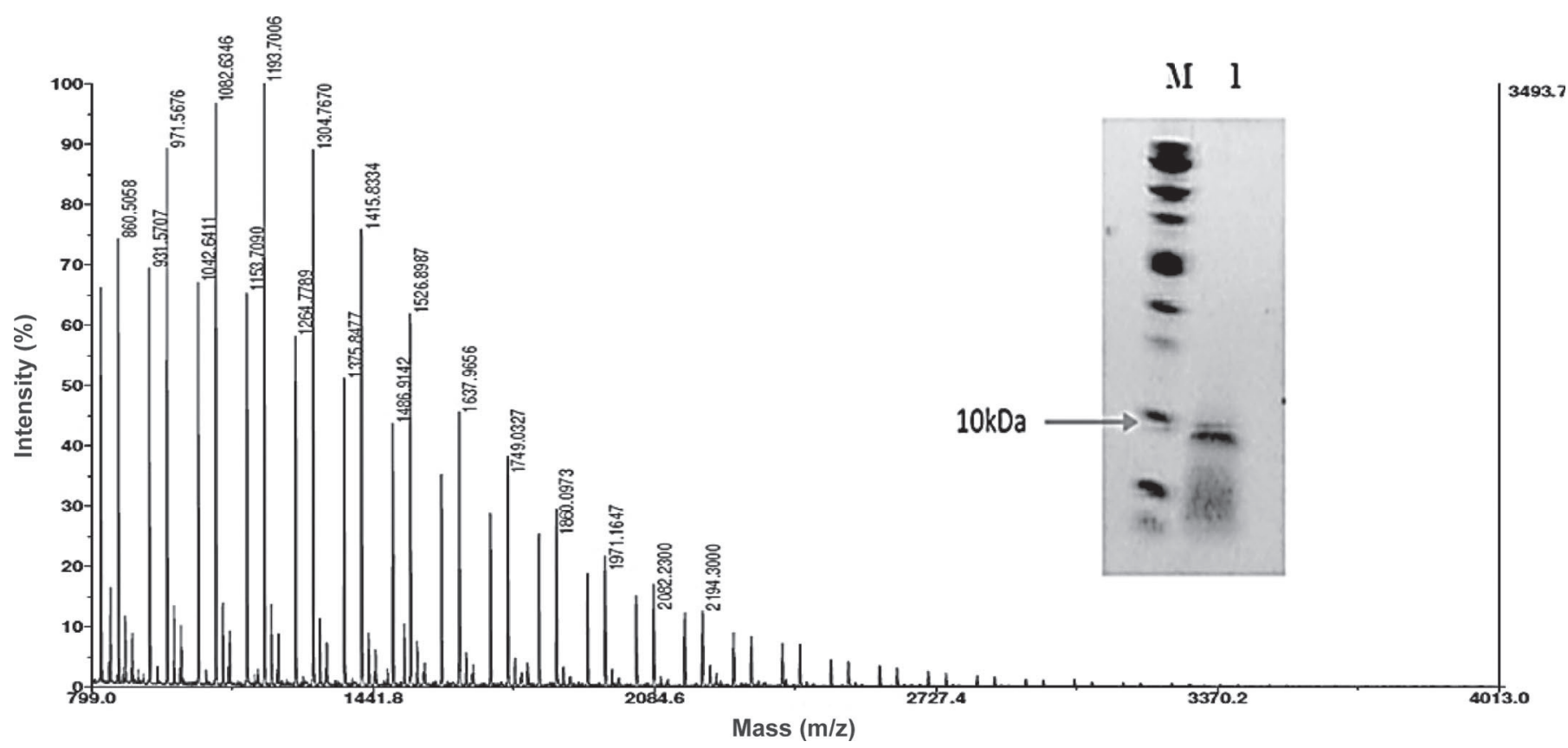

Figure 6. Matrix-assisted laser desorption/ionization time-of-flight spectrum of the digested SDS-PAGE band obtained from the HPLC fraction. $\mathrm{M}=$ marker, lane 1 = active HPLC fraction from Enterococcus faecium.

genome sequence of the producer was searched against the BLAST database, no significant similarity was detected.

\section{Genome Sequencing and Analysis}

In the analysis of genes encoding bacteriocin production with RAST server, one gene cluster with colicin production was detected. A bacteriocin of high molecular weight $(>5 \mathrm{kDa})$ that was a phage lysin was also detected. After checking with Bactibase database (http://bactibase.pfba-lab-tun.org/blast), the sequence showed $14 \%$ similarity to enterolysin A. Furthermore, 16 genes involved in probiotic functions were detected in the bacterial genome and are listed in Table 3. No toxin or superantigen genes were detected in the virulence, disease, and defense category. The genome of the bacteria was compared with the complete genome of the probiotic strain E. faecium T110 with accession number CP006031 in NCBI (Natarajan and Parani, 2015). The comparisons between both strains are listed in Table 4. A total of 43 virulence genes related to Enterococcus spp. were examined and probiotic strain $E$. faecium T110 contained 8 out of the 43 genes, whereas the strain in this study harbored 6 virulence genes.

\section{DISCUSSION}

The producer strain E. faecium $\mathrm{C} 1$ used was isolated during the screening of potential LAB in fermented cow milk to study the effect of their bacteriocin generated by E. faecium $\mathrm{C} 1$. The antimicrobial peptide isolated from this producer strain in the study was shown to produce a novel bacteriocin with large molecular weight. The bacteriocin $\mathrm{BacC} 1$ was heat $\left(25\right.$ to $\left.60^{\circ} \mathrm{C}\right)$ and $\mathrm{pH}(2$ to $6)$ stable. The enzyme stability test results showed that the sample was proteinaceous in nature. The bacteriocin was active against both gram-positive and gramnegative bacteria. To ensure that the producer strain is a safe microorganism and, importantly, not vancomycin resistant, we carried out hemolysis and antibiotic susceptibility tests. The results showed that the $E$. faecium $\mathrm{C} 1$ was a nonhemolytic strain and sensitive to ampicillin, chloramphenicol, penicillin $\mathrm{V}$, tetracycline, and vancomycin, based on CLSI standards. No interpretation is available for amoxicillin, but according to CLSI, enterococci that are susceptible to penicillin are predictably susceptible to ampicillin and amoxicillin. Moreover, CLSI states that clindamycin may appear active in vitro but is not effective clinically and should not be reported as susceptible. Therefore, resistance to clindamycin is not an issue in our strain. However, the strain was resistant to 1 unit of penicillin G (1 unit is equivalent to $0.6 \mu \mathrm{g}$ ), which is probably due to the lower concentration of penicillin $\mathrm{G}$ used compared with the higher sensitivity of $10 \mu \mathrm{g}$ of penicillin $\mathrm{V}$ used. Because of the opportunistic nature of the enterococci, it is crucial to select only nonvirulent and non-antibiotic-resistant strains of enterococci for use in the food industry (Franz et al., 2003). 
Table 3. List of genes for probiotic functions in Enterococcus faecium $\mathrm{C} 1$

\begin{tabular}{llrl}
\hline Gene & Location & Gene size $(\mathrm{bp})$ & Annotation \\
\hline 1 & Contig_141_16802_16026 & 777 & Sortase A, LPXTG specific \\
2 & Contig_141_33240_32677 & 564 & Sortase A, LPXTG specific \\
3 & Contig_288_6552_7223 & 672 & Sortase A, LPXTG specific \\
4 & Contig_288_9267_10019 & 753 & Sortase A, LPXTG specific \\
5 & Contig_382_89436_89891 & 456 & Sortase A, LPXTG specific \\
6 & Contig_73_94496_95656 & 1,161 & Sortase A, LPXTG specific \\
7 & Contig_86_51029_50136 & 894 & Sortase A, LPXTG specific \\
8 & Contig_382_79966_80673 & 708 & ABC-type antimicrobial peptide transport system, permease component \\
9 & Contig_382_80685_81038 & 354 & ABC-type antimicrobial peptide transport system, permease component \\
10 & Contig_71_64732_64601 & 132 & ABC-type antimicrobial peptide transport system, permease component \\
11 & Contig_71_64868_64725 & 144 & ABC-type antimicrobial peptide transport system, permease component \\
12 & Contig_73_115518_117320 & 1,803 & ABC-type antimicrobial peptide transport system, permease component \\
13 & Contig_288_23850_25055 & 1,206 & Phage lysin (EC 3.2.1.17) \\
14 & Contig_231_97574_97035 & 540 & Colicin V production protein \\
15 & Contig_86_51575_51300 & 276 & Cell wall surface anchor family protein, LPXTG motif \\
16 & Contig_86_52612_51575 & 1,038 & Cell wall surface anchor family protein, LPXTG motif \\
\hline
\end{tabular}

The E. faecium $\mathrm{C} 1$ was isolated from fermented milk simulated in the laboratory. Enterococci can be found naturally in the gastrointestinal tract and are widely used as starter cultures in many fermented food products. The antimicrobial activity of E. faecium is caused by bacteriocins and has been widely investigated and discussed (Kang and Lee, 2005). The bacteriocin produced by the strain in this study was different from the common enterocin reported. The common bacteriocins produced by E. faecium are enterocin A with $47 \mathrm{AA}$ residues and a molecular weight of $4.829 \mathrm{kDa}$ (Aymerich et al., 1996), enterocin B with 53 AA residues and a molecular weight of $5.465 \mathrm{kDa}$ (Casaus et al., 1997), and enterocin $\mathrm{P}$ with $44 \mathrm{AA}$ residues and a theoretical molecular weight of $4.493 \mathrm{kDa}$ (Cintas et al., 1997). The peptide extracted in this study was larger than the known enterocins but smaller than enterolysin, which is $34.501 \mathrm{kDa}$ and has $316 \mathrm{AA}$ residues (Nilsen et al., 2003).

The data suggest that one mode of action of the proposed bacteriocin might involve membrane disruption of the targeted cell. The effect of bacteriocin BacC1 can be seen clearly in the transmission electron microscopy images, where the test bacteria cell envelopes were completely destroyed by the action of bacteriocin. The membrane permeability test also demonstrates that $\mathrm{BacC} 1$ shears the membrane of the bacteria and enables the fluorescence dye to bind with the bacterial nucleic acid. The SYTOX green dye has high affinity toward nucleic acids and is not able to permeate the intact membranes of living cells (Roth et al., 1997). A similar testing method was used previously to detect membrane disruption of salivaricin 9 from Streptococcus salivarius (Barbour et al., 2013).

Table 4. Absence and presence of different virulence genes ${ }^{1}$ between Enterococcus faecium $\mathrm{C} 1$ and Enterococcus faecium T110

\begin{tabular}{|c|c|c|c|}
\hline Category/gene & Function & $\begin{array}{l}\text { E. faecium } \\
\text { C1 }\end{array}$ & $\begin{array}{c}\text { E. faecium } \\
\text { T-110 }\end{array}$ \\
\hline \multicolumn{4}{|l|}{ Adherence } \\
\hline Acm & Adhesion of collagen from E. faecium & + & + \\
\hline Scm & Second collagen adhesion of $E$. faecium & - & + \\
\hline $\operatorname{SagA}$ & Aggregation substance & + & + \\
\hline EfaAfm ${ }^{2}$ & Cell wall adhesins & + & + \\
\hline \multicolumn{4}{|l|}{ Antiphagocytosis } \\
\hline$C d s A^{2}$ & Host immune evasion & + & + \\
\hline$U p p S^{2}$ & Host immune evasion & + & + \\
\hline \multicolumn{4}{|c|}{ Biofilm formation } \\
\hline BopD & Biofilm formation & + & + \\
\hline \multicolumn{4}{|l|}{ Exoenzyme } \\
\hline \multicolumn{4}{|l|}{ Hyaluronidase } \\
\hline EF0818 & Exoenzyme, biofilm formation & - & + \\
\hline
\end{tabular}

${ }^{1}$ List of virulence factors were taken from the genomes of Enterococcus species at virulence factor database (http://www.mgc.ac.cn/VFs/). Genes that differ between the 2 strains are shown in bold.

${ }^{2}$ Amino acid sequence from UniProt (http://www.uniprot.org/). 
The same motif discovered in this study (GPXGPX) was reported in a previous study of a bacteriocin produced by E. faecium FL31 but located in the middle of the sequence (Chakchouk-Mtibaa et al., 2014). In the current study, this novel motif was uniquely located at the N-terminal end of the bacteriocin sequence. Hydroxyproline with a hydroxyl $(\mathrm{OH})$ group attached to the gamma $\mathrm{C}$ atom is produced by hydroxylation of proline. Bacteriocin BacFL31 produced by E. faecium FL31 is the first bacteriocin reported to contain hydroxyproline residues. Interestingly, these are novel and unique characteristics of bacteriocins produced by this genus and not frequently reported in other genera. Hydroxyproline is a major component of collagen and is found in collagen-like proteins in animals and in many glycoproteins in plants. Hydroxyproline plays an important role in maintaining collagen's triple-helix structure and stability (Jenkins and Raines, 2002). This modified AA is also present in peptide antibiotics such as in $\beta$-ring of actinomycins produced by Streptomyces spp. and microbisporicin produced by Microbispora spp. (Castiglione et al., 2008; Bitzer et al., 2009; Foulston and Bibb, 2010). We were unable to detect the operon of the bacteriocin in the bacterial genome because the operon encoding production and immunity is carried within the plasmid or the gaps of the genome, which were not completely sequenced. The possibility of the operon being harbored within the plasmid is very high because many bacteriocins purified from enterococci are frequently associated with plasmids (Franz et al., 2007).

Among the virulence genes examined, the bacteria contained 3 out of 15 genes related to adherence. Compared with the probiotic strain E. faecium T-110, E. faecium $\mathrm{C} 1$ did not produce $S \mathrm{~cm}$, which is the second collagen adhesion gene. Enterococcus faecium $\mathrm{C} 1$ also lacked the gene encoding production of hyaluronidase. In the antiphagocytosis category, we checked for 13 genes using the BLAST database and only 2 genes ( $C d s A$ and Upps) were detected that encode for essential protein in other bacteria, including E. faecium T-110 that is safely used as a probiotic (Thurlow et al., 2009). In the category for biofilm production, although the $B o p D$ gene was present, it may not be expressed due to the absence of the $f s r A B C$ operon (Bourgogne et al., 2006; Natarajan and Parani, 2015).

When added to milk, the bacteria resulted in a significant reduction of naturally occurring microorganisms in terms of total count (colony-forming units). Therefore, the bacterial culture can be directly added to milk to reduce or inhibit total microbial count and, at the same time, enhance the flavor and taste of the milk. Another possible application of this strain is in cheese making (Gardiner et al., 1999; Giraffa, 2003).
The bacteriocin produced by the strain can also be used as a commercial additive to extend the shelf life of food products.

The application of bacteriocins, either as additives or by utilizing in situ production by the producer $E$. faecium $\mathrm{C} 1$, is promising. When live cultures generating such bacteriocins are used in foods, the bacteriocin producers either substitute for all or part of the starter or subsequently act as a protective culture to improve the safety of the food products (O'Sullivan et al., 2002; Leroy et al., 2003). Studies have also shown that bacteriocins produced in situ by producer strains or added exogenously are highly effective in inhibiting the growth of other bacteria, especially when combined with moderate heat treatment in dairy products $(\mathrm{Mu}-$ ñoz et al., 2007). In ex situ production of bacteriocin, the producer strains are grown on a large scale, after which the bacteriocins are recovered and added to food in partially or completely purified concentrates, which would require approval from regulatory agencies for use as an additive. However, only a small amount of bacteriocin is usually recovered, leading to high processing costs. Although bacteriocin production by inoculation with the producer strain is more cost effective, production is influenced by many factors, including physicochemical factors and food composition. Under optimum conditions and environment, bacteriocins are ideally produced in the food (Gálvez et al., 2007).

\section{CONCLUSIONS}

Bacteriocin BacC1, with molecular weight of $10 \mathrm{kDa}$ and a partial AA sequence of GPXGPXGP, was successfully extracted from an Enterococcus faecium strain isolated from fermented milk samples. The bacteriocin showed significant antimicrobial activity against selected test bacteria. The strain and the bacteriocin produced are potential antimicrobial agents that could be used to extend the shelf life of food products. The genome sequence of the bacterium confirmed that the strain has no significant virulence factor and is not vancomycin resistant.

\section{ACKNOWLEDGMENTS}

The authors acknowledge support by way of facilities from University of Malaya and the High Impact Research-Malaysian Ministry of Higher Education grant designated as UM.C/625/1/HIR/MOHE/SC/08 with account F000008-21001 under the principal investigator Koshy Philip for the study. The funders had no role in study design, data collection and analysis, decision to publish, or preparation of the manuscript. 


\section{REFERENCES}

Andersson, A., U. Rönner, and P. E. Granum. 1995. What problems does the food industry have with the spore-forming pathogens $B a$ cillus cereus and Clostridium perfringens. Int. J. Food Microbiol. $28: 145-155$.

Aymerich, T., H. Holo, L. S. Håvarstein, M. Hugas, M. Garriga, and I. F. Nes. 1996. Biochemical and genetic characterization of enterocin A from Enterococcus faecium, a new antilisterial bacteriocin in the pediocin family of bacteriocins. Appl. Environ. Microbiol. 62:1676-1682.

Barbour, A., K. Philip, and S. Muniandy. 2013. Enhanced production, purification, characterization and mechanism of action of salivaricin 9 lantibiotic produced by Streptococcus salivarius NU10. PLoS ONE 8:e77751.

Ben Omar, N., A. Castro, R. Lucas, H. Abriouel, N. M. Yousif, C. M. Franz, W. H. Holzapfel, P.-P. Rubén, M. Martínez-Canãmero, and A. Gálvez. 2004. Functional and safety aspects of enterococci isolated from different Spanish foods. Syst. Appl. Microbiol. 27:118-130.

Bitzer, J., M. Streibel, H. J. Langer, and S. Grond. 2009. First Y-type actinomycins from Streptomyces with divergent structure-activity relationships for antibacterial and cytotoxic properties. Org. Biomol. Chem. 7:444-450.

Bourgogne, A., S. G. Hilsenbeck, G. M. Dunny, and B. E. Murray. 2006. Comparison of OG1RF and an isogenic fsrB deletion mutant by transcriptional analysis: The Fsr system of Enterococcus faecalis is more than the activator of gelatinase and serine protease. J. Bacteriol. 188:2875-2884.

Casaus, P., T. Nilsen, L. M. Cintas, I. F. Nes, P. E. Hernández, and H. Holo. 1997. Enterocin B, a new bacteriocin from Enterococcus faecium T136 which can act synergistically with enterocin A. Microbiology 143:2287-2294.

Castiglione, F., A. Lazzarini, L. Carrano, E. Corti, I. Ciciliato, L. Gastaldo, P. Candiani, D. Losi, F. Marinelli, E. Selva, and F. Parenti. 2008. Determining the structure and mode of action of microbisporicin, a potent lantibiotic active against multiresistant pathogens. Chem. Biol. 15:22-31.

Chakchouk-Mtibaa, A., L. Elleuch, S. Smaoui, S. Najah, I. Sellem, S. Abdelkafi, and L. Mellouli. 2014. An antilisterial bacteriocin BacFL31 produced by Enterococcus faecium FL31 with a novel structure containing hydroxyproline residues. Anaerobe 27:1-6.

Christiansson, A., J. Bertilsson, and B. Svensson. 1999. Bacillus cereus spores in raw milk: Factors affecting the contamination of milk during the grazing period. J. Dairy Sci. 82:305-314.

Cintas, L. M., P. Casaus, L. S. Håvarstein, P. E. Hernandez, and I. F. Nes. 1997. Biochemical and genetic characterization of enterocin P, a novel sec-dependent bacteriocin from Enterococcus faecium P13 with a broad antimicrobial spectrum. Appl. Environ. Microbiol. 63:4321-4330

CLSI (Clinical and Laboratory Standards Institute). 2007. Performance Standards for Antimicrobial Susceptibility Testing; Seventeenth Informational Supplement. CLSI document M100-S17. CLSI, Wayne, PA.

Cotter, P. D., R. P. Ross, and C. Hill. 2013. Bacteriocins-A viable alternative to antibiotics? Nat. Rev. Microbiol. 11:95-105.

Deegan, L. H., P. D. Cotter, C. Hill, and P. Ross. 2006. Bacteriocins: Biological tools for bio-preservation and shelf-life extension. Int. Dairy J. 16:1058-1071.

du Toit, M., C. Franz, L. Dicks, and W. Holzapfel. 2000. Preliminary characterization of bacteriocins produced by Enterococcus faecium and Enterococcus faecalis isolated from pig faeces. J. Appl. Microbiol. 88:482-494.

Foulquié Moreno, M. R., P. Sarantinopoulos, E. Tsakalidou, and L. De Vuyst. 2006. The role and application of enterococci in food and health. Int. J. Food Microbiol. 106:1-24.

Foulston, L. C., and M. J. Bibb. 2010. Microbisporicin gene cluster reveals unusual features of lantibiotic biosynthesis in actinomycetes. Proc. Natl. Acad. Sci. USA 107:13461-13466.
Franz, C. M., M. Huch, H. Abriouel, W. Holzapfel, and A. Gálvez. 2011. Enterococci as probiotics and their implications in food safety. Int. J. Food Microbiol. 151:125-140.

Franz, C. M., M. E. Stiles, K. H. Schleifer, and W. H. Holzapfel. 2003 Enterococci in foods - A conundrum for food safety. Int. J. Food Microbiol. 88:105-122.

Franz, C. M., M. J. van Belkum, W. H. Holzapfel, H. Abriouel, and A. Galvez. 2007. Diversity of enterococcal bacteriocins and their grouping in a new classification scheme. FEMS Microbiol. Rev. $31: 293-310$.

Gálvez, A., H. Abriouel, R. L. Lopez, and N. Ben Omar. 2007. Bacteriocin-based strategies for food biopreservation. Int. J. Food Microbiol. 120:51-70.

Gardiner, G. E., R. P. Ross, J. M. Wallace, F. P. Scanlan, P. P. Jägers, G. F. Fitzgerald, J. K. Collins, and C. Stanton. 1999. Influence of a probiotic adjunct culture of Enterococcus faecium on the quality of cheddar cheese. J. Agric. Food Chem. 47:4907-4916.

Giraffa, G. 2003. Functionality of enterococci in dairy products. Int J. Food Microbiol. 88:215-222.

Izquierdo, E. Y. Cai, E. Marchioni, and S. Ennahar. 2009. Genetic identification of the bacteriocins produced by Enterococcus faecium IT62 and evidence that bacteriocin 32 is identical to enterocin IT. Antimicrob. Agents Chemother. 53:1907-1911.

Jenkins, C. L., and R. T. Raines. 2002. Insights on the conformational stability of collagen. Nat. Prod. Rep. 19:49-59.

Kang, J., and M. Lee. 2005. Characterization of a bacteriocin produced by Enterococcus faecium GM-1 isolated from an infant. J. Appl. Microbiol. 98:1169-1176.

Klaenhammer, T. R. 1993. Genetics of bacteriocins produced by lactic acid bacteria. FEMS Microbiol. Rev. 12:39-85.

Leroy, F., M. R. Foulquie Moreno, and L. De Vuyst. 2003. Enterococcus faecium RZS C5, an interesting bacteriocin producer to be used as a co-culture in food fermentation. Int. J. Food Microbiol 88:235-240.

Muñoz, A., S. Ananou, A. Gálvez, M. Martínez-Bueno, A. Rodríguez, M. Maqueda, and E. Valdivia. 2007. Inhibition of Staphylococcus aureus in dairy products by enterocin AS-48 produced in situ and ex situ: bactericidal synergism with heat. Int. Dairy J. 17:760769 .

Natarajan, P., and M. Parani. 2015. First complete genome sequence of a probiotic Enterococcus faecium strain T-110 and its comparative genome analysis with pathogenic and non-pathogenic Enterococcus faecium genomes. J. Genet. Genomics 42:43-46.

Nilsen, T., I. F. Nes, and H. Holo. 2003. Enterolysin A, a cell wall-degrading bacteriocin from Enterococcus faecalis LMG 2333. Appl Environ. Microbiol. 69:2975-2984

O'Sullivan, L., R. P. Ross, and C. Hill. 2002. Potential of bacteriocinproducing lactic acid bacteria for improvements in food safety and quality. Biochimie 84:593-604.

Pingitore, E. V., E. Salvucci, F. Sesma, and M. E. Nader-Macias. 2007. Different strategies for purification of antimicrobial peptides from lactic acid bacteria (LAB). Commun. Curr. Res. Educ. Topics Trends Appl. Microbiol. 1:557-568.

Rehaiem, A., Z. B. Belgacem, M. R. Edalatian, B. Martínez, A. Rodrí guez, M. Manai, and N. P. Guerra. 2014. Assessment of potential probiotic properties and multiple bacteriocin encoding-genes of the technological performing strain Enterococcus faecium MMRA. Food Contr. 37:343-350.

Roth, B. L., M. Poot, S. T. Yue, and P. J. Millard. 1997. Bacterial viability and antibiotic susceptibility testing with SYTOX green nucleic acid stain. Appl. Environ. Microbiol. 63:2421-2431.

Stiles, M. E., and W. H. Holzapfel. 1997. Lactic acid bacteria of foods and their current taxonomy. Int. J. Food Microbiol. 36:1-29.

Thurlow, L. R., V. C. Thomas, and L. E. Hancock. 2009. Capsular polysaccharide production in Enterococcus faecalis and contribution of CpsF to capsule serospecificity. J. Bacteriol. 191:62036210 .

Yi, H., L. Zhang, Y. Tuo, X. Han, and M. Du. 2010. A novel method for rapid detection of class IIa bacteriocin-producing lactic acid bacteria. Food Contr. 21:426-430. 